\title{
When it is Not Logically Necessary for a Necessary Condition of Value to be Valuable
}

\section{Michael Kowalik}

\begin{abstract}
The premise that it is logically necessary for a necessary condition of value to be valuable is sometimes used in metaethics in support of the claim that agency, or some constitutive condition of agency or action, has value for all agents. I focus on the most recent application of this premise by Caroline T. Arruda and argue that the premise is false. Despite this defect the relevant evaluative step could still work just in case of agency if an additional condition were satisfied.
\end{abstract}

\section{Keywords}

Metaethics, Normative Reasons, Logical Consequence 


\section{Introduction}

The premise that it is logically necessary for a necessary condition of value to be valuable is sometimes used in metaethics in support of the claim that agency, or some constitutive condition of agency or action, has value for all agents. I focus on the most recent and most rigorous argument defending this premise by Caroline T. Arruda and argue that the premise is false. The present argument poses a challenge to the Constructivist branch of metaethics, in the tradition of Alan Gewirth and Christine Korsgaard.

To answer the question 'Why care about being an agent?' Arruda $(2016,11)$ sets out to identify hypothetical (agency dependent) reasons that "have the right kind of content" to give us universally normative or objective reasons. She submits that there is such a reason: "caring about full-blown agency is a condition for engaging in activities that we value". Arruda $(2016,2)$ defines full-blown agency only provisionally, as requiring the following basic capacities: (1) the capacity for sound, rational deliberation; (2) the capacity to act autonomously; (3) the capacity for self-control. Since the "the issue of the necessary and sufficient conditions for full-blown agency is beyond [the scope of Arruda's paper]" I take "full-blown agency" to signify a special kind of agency.

The way I understand the supporting argument is as follows. We all care about some specific activities, which need not be the same for all agents, for which the capacities for full-blown agency are required. Since the capacities for full-blown agency are a necessary condition of some of the activities that we happen to care about we must also care about exercising the capacities for full-blown agency as a matter of conceptual necessity.

In her own words:

"...as long as one cares about the activities for which one must be a full-blown agent, one must also care about being a full-blown agent. (...) My point is that it is conceptually necessary that if one cares about the pursuit of an end for which aiming at full-blown agency is a condition, one cares (noninstrumentally but nonetheless hypothetically) about being a full-blown agent." $(2016,9)$

Arruda $(2016,10)$ explains the sense of 'to care about' roughly as follows: if we care about something then we judge that it would be, all things considered, worse if we had lacked it. I take this to mean that to care about exercising something is not merely to exercise it but to value that something: its existence, availability or presence.

The logical structure of Arruda's argument can be expressed with the following formula:

for all agents (there is some $\mathrm{X}$ that has positive value)

and (there is $\mathrm{Y}$ which is a necessary condition of $\mathrm{X}$ )

therefore ( $\mathrm{Y}$ has positive value)

Although the same logical structure has been employed by Gewirth ${ }^{1}$ and Korsgaard ${ }^{2}$ (who assume it to be valid without explicitly arguing in its defence) I will focus on the rigorous argument developed by Arruda to show that the general principle expressed above, namely, that it is logically necessary for a necessary condition of value to be valuable, is false. I will also consider subject to what conditions are general inferences about the value of a condition based on the value of a conditional outcome (henceforth, a 'conditional') logically permissible.

1 "... every agent implicitly makes evaluative judgements about the goodness of his purposes and hence about the necessary goodness of the freedom and well-being that are necessary conditions of his acting to achieve his purposes." Gewirth $(1978,48)$

2 "Since you cannot act without reasons and your humanity is a source of your reasons, you must value your own humanity if you are to act at all." Korsgaard $(1996,123)$ 


\section{The Problem}

Arruda does not claim that all agents care about all the activities for which one must be a full-blown agent. I know for a fact that I not only 'do not care about' but disdain certain activities. Arruda (2016, 12) acknowledges that "It is possible not to care about activities for which being a full-blown agent is a necessary condition", but this fact, she claims, does not undercut universal normative force of reasons that obtain from the activities that we do care about.

Let us assume that Arruda's claim is true. Let us then provisionally substitute 'disdain' for 'care about' in her declaration and reflect on the result:

'as long as one disdains the activities for which one must be a full-blown agent, one must also disdain being a full-blown agent.'

We should be able to combine the two versions, 'to care about' and 'disdain', since both seem realistic:

'as long as one cares about or disdains some activities for which one must be a full-blown agent, one must also care about or disdain being a full-blown agent.'

But the resulting formulation no longer has any normative force; it is trivial.

It may be objected that substitution of 'disdain' for 'care about' alters the logical structure of the problem: a necessary condition must be satisfied for the cared about conditional to be realised, while avoiding a necessary condition is not always necessary to prevent the disdained conditional from being realised. In other words, it is not always necessary to avoid a specific necessary condition of $X$ in order to prevent $X$, as there may be other necessary conditions and therefore other ways of preventing $\mathrm{X}$. For the relevant substitution not to alter the logical structure of the problem, the necessary condition of $\mathrm{X}$ must also be either a sufficient condition, or the only non-sufficient condition that can be practically avoided in order to prevent X. In either case, there must be a single condition whose avoidance is a practical, rational or otherwise valued way of preventing the disdained conditional outcome. For example, cigarette smoking is not a sufficient condition of smoking-related cardiovascular disease but its avoidance is the only practicable way of preventing the disease.

For the present argument to work it is sufficient to show that, for some agents, positive instrumental value of a condition does not preclude negative instrumental value of the same condition, provided that satisfaction of the relevant condition is necessary for a positive outcome $\mathrm{X}$ and its nonsatisfaction is practically necessary to avoid a negative outcome Y. Another way, it must be possible for two conditional outcomes that are positive in value to practically depend on the same condition being, respectively, necessarily satisfied and necessarily not-satisfied.

It seems logical that if $\mathrm{Y}$ is a necessary condition of $\mathrm{X}$ and $\mathrm{I}$ am committed to $\mathrm{X}$, then $\mathrm{I}$ am also committed to $\mathrm{Y}$, otherwise my commitment to $\mathrm{X}$ would be incomplete and possibly inconsistent. For example, if I am committed to safe driving but not to wearing seatbelts or to obeying traffic signals, the authorities may argue that I am not in fact committed to safe driving on account of my noncompliance with the road rules. But this evaluative principle does not always hold true. ${ }^{3}$ Following the outline of my argument presented above, let us consider the case of being committed to the positive value of $\mathrm{X}$ and $\mathrm{Z}$, where $\mathrm{Y}$ is a necessary condition of $\mathrm{X}$ and the avoidance of $\mathrm{Y}$ is a necessary condition of Z. To put it differently, attribution of value to a necessary condition on the basis of value of a conditional cannot be accomplished if there are some instances of the conditional that are instrumentally opposite in value. For example, smoking tobacco is a necessary condition of smokingrelated cardiovascular disease and a necessary condition of enjoying the smoking experience. If I positively value the prevention of cardiovascular disease as well as the enjoyment of smoking then, in order to enjoy smoking, I must expose myself to an increased risk of cardiovascular disease and, in

\footnotetext{
3 "...infection makes penicillin valuable, but infection isn't therefore valuable, much less intrinsically valuable." (Markovits 2014, 105)
} 
order to avoid the increased risk of cardiovascular disease I must forgo the enjoyment of smoking. Since the same necessary condition applies to both the positive and the negative outcomes of smoking, and the negative outcome cannot be practically avoided any other way, then it is not logically necessary to attribute definite instrumental value to smoking just because it has a positively valued outcome. ${ }^{4}$

What made the first example seem uncontroversial is that obeying the road rules is, in every case where road rules apply, commonly regarded as a necessary condition of only a positively valued outcome: safe driving.

We can modify the formula expressing the logical structure of the evaluative principle to loosely fit the second example, for at least some agents, but without altering the conclusion:

for some agents (there is $X$ that has positive value and $\mathrm{Z}$ that has negative value) and (there is $\mathrm{Y}$ which is a necessary condition of $\mathrm{X}$ and a sufficient condition of $\mathrm{Z}$ ) therefore (Y has positive value)

The conclusion now does not follow from the premises, since $\mathrm{Y}$ has both positive and negative aspects and it is unclear which aspect has more weight.

I will conclude this section by formulating the problem in the actual terms of Arruda's argument. The capacities for full-blown agency are a necessary condition for acting consistently, which is something that is generally positively valued or cared about (commitment to consistency underwrites the normative force of Arruda's argument) ${ }^{5}$, but also a necessary and plausibly sufficient condition for some instances of acting intentionally but inconsistently on account of flawed deliberation, ${ }^{6}$ which is something that is valued negatively by the force of Arruda's argument.

We can try to avoid the complex and possibly controversial implications of 'acting intentionally but inconsistently' by presenting the second (negative) premise in less abstract terms:

The capacities for full-blown agency are a necessary and sufficient condition of some activities whose absence or avoidance we value, for example, activities that result (or are expected to result) in states of regret, shame or physical pain.

Paradoxically, I may value something - for example, preservation of the life of another - for which the destruction of my own capacities for full-blown agency is practically necessary under some unavoidable circumstances, but the same capacities are also necessary to accomplish the necessary destruction. We now have realistic but contradictory value-commitments stemming from the disputed premise.

Attribution of positive value to full-blown agency on the basis of the positive value of some conditional outcome may be frustrated by the negative value of other conditional outcomes that are unavoidable for full-blown agents who are committed to positively value the former outcome.

\section{The Solution}

The most direct solution to the problem would be to show that for all agents, every action intended by an agent is valuable to that agent at the time of intending because it is preferred above all other actions believed to be possible under the relevant circumstances, irrespective of its negatively valued

\footnotetext{
${ }^{4}$ For a similar argument see Kerstein $(2001,37)$.

5 "I have shown that if one cares about one's capacity for agency, then one should (by virtue of consistency) care about how one exercises it." (Arruda 2016, 10).

6 "...'consistency' is a requirement of rationality rather than a capacity distinctive of full-blown agency" (Arruda 2016, 10) and no real agent is always perfectly consistent. Cf. "it is impossible for an agent to be essentially infallible or perfectly rational by nature." (Lavin 2004, 449).
} 
consequences. This view, which may be called value-internalism about reasons, is defended by Joseph $\mathrm{Raz}^{7}$, but there are also some strong arguments against it. ${ }^{8}$

If value-internalism about reasons were shown to be true then the evaluative principle employed by Arruda could succeed, since the sought after result would no longer be frustrated by possible inconsistency of the underwriting value-commitments. But this would not necessarily save Arruda's normative conclusion.

If all agents value all of their own intentional actions at the time of intending, because these are the preferred actions under the circumstances, and only this kind of valuation counts towards objective or universal value of full-blown agency, we must then value equally those actions that are favourable to full-blown agency as well as those that are detrimental to it, for example, taking strong painkillers or committing suicide, so that our value commitments to full-blown agency are still inconsistent. Generalising about the value of a condition based on the value of its conditional fails again.

An additional consequence of formulating the value of conditionals in a flatly positive way is that it takes away their normative force. The logical structure collapses to what Setiya $(2003,380)$ described as only acting on my reasons rather than good reasons on which to act, and therefore not reasons that are consistently normative. Any normative principle declaring some actions as bad or of negative value for the agent at the time of intending would be contradicting a necessary condition of its own authority: that all actions are good or valuable for the agent at time of intending.

If normative reasons of the right kind cannot obtain from the activities that we value only contingently we could still approach the problem by capitalising on the second-order preference for 'acting in a particular way' that every agent commits to when acting intentionally, irrespective of whether the intended action has positive value for the agent. If to prefer something is to value that something then preferring to 'act in a particular way' is to value 'acting in a particular way', which is just what it means to be an agent. The second-order value-commitment about acting is therefore also a value-commitment about being an agent. Assuming that this approach could be made to work for full-blown agency, there still would be nothing to show that agents have normative reasons to be agents, let alone full-blown agents, just because they value certain activities for which the capacities for full-blown agency are necessary, but only that all agents are implicitly committed to value their own agency by intending to act in a particular way, irrespective of the value of the intended act. Another way, we value our agency because in acting intentionally we show preference for acting in a particular way, not because we value some activities for which agency is necessary.

It seems that the problem discussed here is fatal to Arruda's argument, and by implication to Gewirth's and Korsgaard's arguments, which may be too 'thin' to yield any normative force of practical consequence.

\section{Conclusion}

Arruda's argument hinges on the premise that if we value certain activities for which the capacities for full-blown agency are necessary then we must also value the capacities for full-blown agency. I have argued that the capacities for full-blown agency are not only a necessary condition of activities that we value but also a necessary and plausibly sufficient condition of some activities or states whose absence or avoidance we value. It follows from the above premise that if we value the absence or avoidance of certain activities or states, and such absence or avoidance can be accomplished only through avoidance of exercising the capacities for full-blown agency, then we must also value the

\footnotetext{
7 "...the classical approach, it may be called, can be characterized as holding that the central type of human action is intentional action; that intentional action is action for a reason; and that reasons are facts in virtue of which those actions are good in some respect and to some degree." (Raz 1999, 22); "...having intentions involves belief in the value of what they intend" (Raz 2015, 1); see also (Schueler 2003, 104) (Gewirth 1978, 48-53) (Nagel 1970, 35) (Anscombe 1957, 75-76).

${ }^{8}$ (Stocker 1979) (Velleman 1992) (Setiya 2003) (Setiya 2007).
} 
absence or avoidance of the capacities for full-blown agency, therefore a contradiction, therefore the premise (insofar as it involves conceptual necessity) is false.

Most explicitly, I may value and desire to preserve the life of another for what the destruction of my own capacities for full-blown agency are practically necessary, but the same capacities are also necessary to accomplish the necessary destruction.

I have shown that it is possible to defend the controversial premise by committing to the first-order thesis that all agents value all of their own intentional actions at the time of intending, or the secondorder thesis that all agents are committed to value 'acting in a particular way' whenever they act intentionally, but these remedies come at the cost of, respectively, contradicting or bypassing the normative aim of the argument.

Nothing said here purports to question rationality of contingently valuing the capacities for fullblown agency because one values some activities for which the capacities for full-blown agency are necessary. I have argued only that it is not logically necessary to value the capacities for full-blown agency just because one values some activities for which the capacities for full-blown agency are necessary. Based on the present case-study it is evident that, in general, it is not logically necessary for a necessary condition of value to be valuable, although in some cases it may be logically permissible to attribute objective value to the condition on the basis of value of the conditional.

\section{References}

Anscombe, G.E.M. Intention. Cambridge: Harvard University Press, 1957.

Arruda, Caroline T. "Why Care about Being an Agent?" Australasian Journal of Philosophy, 2016.

Gewirth, Alan. Reason and Morality. Chicago: The University of Chicago Press, 1978.

Kerstein, Samuel J. "Korsgaard's Kantian Arguments for the Value of Humanity." Canadian Journal of Philosophy, 2001: 23-52.

Korsgaard, Christine M. The Sources of Normativity. Cambridge: Cambridge University Press, 1996.

Lavin, Douglas. "Practical Reason and the Possibility of Error." Ethics, 2004: 424-457.

Markovits, Julia. Moral Reason. Oxford: Oxford University Press, 2014.

Nagel, Thomas. The Possibility of Altruism. Oxford: Clarendon Press, 1970.

Raz, Joseph. Engaging Rerason: On the Theory of Value and Action. Oxford: Oxford University Press, 1999.

Raz, Joseph. Intention and Value. Public Law \& Legal Theory Working Paper, New York: Columbia Law School, 2015.

Schueler, G. F. Reasons and Purposes: Human Rationality and the Teleological Explanation of Action. Oxford: Oxford University Press, 2003.

Setiya, Kieran. "Explaining Action.” The Philosophical Review, 2003: 339-393.

-. Reasons without Rationalism. Princeton and Oxford: Princeton University Press, 2007.

Stocker, Michael. "Desiring the Bad: An Essay in Moral Psychology." The Journal of Philosophy, 1979: 738-53.

Velleman, J.D. “The Guise of the Good.” Nous, 1992: 3-26. 